\title{
Status of University Library Automation in Sri Lanka: A Survey
}

\section{D.G.A.S. Malkanthi ${ }^{1}$}

\begin{abstract}
The automation in libraries has changed the development of the library services. It has changed the library's day to day activities and its functionality in to a speedy process. Patrons do not need to visit each and every section or shelf to find information instead they need just sit in front of a computer with internet. This article will discuss about the status of automation through findings of a survey. The objectives of this study are to identify the status of university library automation in Sri Lanka and identify the problems associated with current automation process and thereby provide effective suggestions to overcome the existing problems. Fifteen (15) main university libraries and 18 faculty libraries were selected other than departmental and institutional libraries. Questionnaire was used to collect primary data from the sample. It was found that $(35 \%)$ of libraries operated successfully with automated systems. (18\%) of libraries had considerably appropriate automated system. Moderately acceptable level of automation process is existing among $37 \%$ of the libraries. Ten percent of libraries were poor in executing the automated system. Because of obstacles, some university libraries are far behind from leading universities. To overcome the issues and challenges, the government should endorse providing financial aid and other facilities. Universities also should have plans with a proper vision to achieve realistic goals in future.
\end{abstract}

Keywords: Library Automation, Automation Software, University Libraries, Sri Lanka

\footnotetext{
${ }^{1}$ Senior Assistant Librarian, Wayamaba University of Sri Lanka, Email:Shyamalim@,wyb.ac.1k
}

(iD) http://orcid.org/0000-0002-7721-7190 


\section{Introduction}

"The most important issue for libraries management is the change without losing their identity. Change is nothing but a transformation of today's requirement to tomorrow's performance is important" (Patel, 2012 p.92).

Libraries are the lighthouse for information; the thirst for knowledge is increasing every day at various levels and in various subjects. As per statistics collected two decades back "The world production of books is around 60 million per year. There are more than 200000 journals. Over ten million research papers are published every year in specialized journals beside those in popular magazine" (Raman, 1995, p.76). Today, there is a great necessity to provide such information quickly on demand for which efficient and accurate devices or tools should be introduced. This situation creates for library automation. Without automating libraries, management of the resource and extracting their optimum utility is impossible. According to Encyclopedia of Library and Information Science, "automation is the technology concerned with the design development of process and system that minimize the necessity of human intervention in operation" (Kent, 1997, p.19). Library automation may be defined as the application of automatic and semiautomatic data processing machines to perform traditional library housekeeping activities such as acquisition, circulation, cataloguing, reference and serials control. Today library automation is a most frequently used term to describe the mechanization of library activities using the computer (Uddin, 2009).

Sri Lanka being a developing country, needs effective library service for achieving developmental goals. As a result, university libraries are playing an important role in higher education sector of the country. The goal of the university library is to fulfill the information needs of the students and academic community. Libraries are now extending their traditional roles to suit to new Information Communication Technology dominant era. Therefore, library automation is essential in this regard.

End of the last century only commercial library software was available for automating integrated library system. Among them good solutions were developed in foreign countries by multinational companies which were not 
affordable to Sri Lanka. Open sources software (OSS) is the outcome of collaborative work of a group of people or institutions. OSS is gaining popularity in libraries especially as an integrated system. Libraries in Sri Lanka were under budgetary restrictions which are the limiting factor in any kind of developments. OSS is a suitable choice that can be used in improving the services with limited cost.

\section{University Library Automation in Sri Lanka}

University Ceylon library was the only university library that was in Sri Lanka till 1959. However with the establishment of new universities libraries with small collections also were evolved. At present there are fifteen (15) university libraries along with their branches which are governed by University Grant Commision (UGC) (Ravimumar \& Ramanan, 2013).

In 1986, there was a turning point in the history of University Library when the first meeting on automating University Libraries was held. In that meeting, Inter University Committee on Librarians (IUCL) accentuated the importance of automating university libraries in order to be on par with the other University Libraries in the world. In 1991, UGC provided one microcomputer to each eight University libraries to commence the ground level work of automation. These are the main university libraries namely, University of Peradeniya, University of Colombo, University of Moratuwa, Open university of Sri Lanka, University of Sri Jayewardenepura, University of Kalaniya, University of Jaffna, and University of Ruhuna.

Non availability of suitable library software could be considered as one of the major reasons for the slow growth of computerized library systems. Introduction of CDS/ ISIS (Computerized Documentation System/ Integrated Information System) software by UNESCO in 1986 and the designation of SLSTIC (Sri Lanka Scientific and Technical Information Center) as the national distributor for the software in 1987 changed the scenario (Talagala \& Gamge, 2003). CDS/ISIS was a great bibliographical package, but it could not support libraries with an integrated library automation system to cover all library housekeeping activities in addition to cataloguing. However, once ISIS is introduced as a Database Management Systems, it made easy for librarians to go to other sophisticated integrated library automation packages. 
LibSys, Alice for Windows, Libsuit, are some of the popular commercial soft wares in Sri Lanka. But many problems were inherent in these commercial products related to maintenance, upgrading and data export etc. Among the eight libraries, the Open University of Sri Lanka had successfully automated their library functions (Talagala \& Gamge, 2003). They have started its automation by computerizing the catalogue in 1991 with ISIS. In 1993, the Open University computerized its circulation system and in 1995 started to use computerized acquisitions with Dbase and started to use WINISIS in 1999.

Due to insufficient capacity of the WINISIS, more University libraries started automation using proprietary software Libsys, which was provided to University libraries by UGC Sri Lanka through a special fund. Those libraries that included in this system were: Open University of Sri Lanka, Eastern University, University of Jaffna, Sabaragamuwa University and Rajarata University (Ramanan \& Ravikumar, 2014).University of Peradeniya library selected Alice for Windows and Moratuwa University library selected Libsys software. Kalaniya University converted their data to Libsuit software while University of Ruhuna created its own integrated library management system by using open source package KOHA (Wijayaratne, 2005). As library professionals in Sri Lanka increasingly recognized the advantages of OSS, many libraries in Sri Lanka successfully implemented it as a cost effective and easy to use solution for automation. There are number of OSS from which libraries can choose according to the nature of library and available staff to manage their library while retaining their individuality.

\section{Objectives}

The objectives of this study were;

- Investigating the status of library automation in Universities in Sri Lanka

- Identification of problems associated with existing systems

- Providing effective suggestions to overcome the existing problems

\section{Study Method}

Survey method was adopted in this research. There are thirty three $(n=33)$ university libraries. The sample was fifteen Sri Lankan national university 
librarians and eighteen branch librarians (Senior Assistant librarians or Assistant librarians) who were in charge of those national university branches libraries. Survey was conducted using structured questionnaire to collect the data on automation situation in University Libraries. The questionnaires were distributed through e- mail among all University librarians and branch librarians who were selected as sample to collect data. Observational visits were also conducted to the libraries to verify the responses. Collected data was analyzed to find present status of the automation using the marking scheme as follows.

Table 1: Marking Scheme to Analyze the Present Situation of the Library Automation

\begin{tabular}{|l|l|}
\hline $\begin{array}{l}\text { Marks } \\
\mathbf{\%}\end{array}$ & $\begin{array}{l}\text { Quality of } \\
\text { Library } \\
\text { Automation }\end{array}$ \\
\hline $1-25$ & Poor \\
\hline $26-50$ & Normal \\
\hline $51-75$ & Good \\
\hline $76-100$ & Excellent \\
\hline
\end{tabular}

\section{Analysis and Discussion}

This study focuses on status of university library automation. Initially almost all university libraries (100\%) started using cataloguing module and online public access catalogue has been available to the readers. $19 \%$ of the university libraries started their automation before year 2000 and $81 \%$ percent of them stared after the year 2000. The study found that non availability of intergraded library software was the main reason for this problem.

After year 2000 open source software usage in Sri Lanka became very popular and universities recruited ICT skilled staff to libraries. These skilled staff used open source software for their library automation and supported other libraries too. At the beginning university libraries have utilized both commercial and open sources software for the automation process. However at present open source software usage is $80 \%$ and mostly used software is KOHA (70\%) 
This study focuses on the benefits that university libraries could achieve from automating library functions. Identified benefits were; automation reduction of manpower (67\%), foster equipment operation $89 \%$, improve quality of production $85 \%$, ability to control levels that would be unachievable with manual control $70 \%$, ability to operate during nonstandard hour's $67 \%$, and handling automated data collection $70 \%$. Seventy Eight percent $(78 \%)$ of selected libraries totally agreed that they had got full benefits from the automation process.

There is evidence to suggest that for some staffing levels automation process is increased job satisfaction, and study has found clerical staff reporting of improved flexibility and creativity in the work done. The majority of library support staff experienced increases in job satisfaction following automation and feel that they were more effective. Without the support of the higher authority university libraries would not achieve their targets, in this scenario the study tries to find out what the opinion of the librarians was on the higher authority support. According to the results regarding support from the mother organization to the library $30 \%$ was highly satisfied, $60 \%$ was satisfy and $10 \%$ was not satisfied. Within these unsatisfied libraries, some of them are branch libraries.

In the automation process, there are several preliminary requirements that should be considered. In this regard the library must prepare a budget allocation for the purpose. In this study several infrastructure categories were identified and the librarians were requested to indicate how they allocate their budget for those categories. Result revealed that hardware purchasing was $73 \%$, while most of the universities used library capital allocation to get hardware and some university libraries received hardware free of charge from several projects $(11 \%)$. Twenty six percent of libraries (26\%) spent their allocation on software installation while libraries open sources software had the installation done free of charge (65\%). Maintenance and development cost for some commercial software was (15\%) these libraries spent 1-5 million rupees as the license fee annually. Sixty five percent (65\%) of university libraries maintained and developed their systems using library staff. 
One of the main objectives of this study was to identify the status of library automation in Universities in Sri Lanka. As shown in Figure 1 below, almost all University Libraries had achieved their targets in the automation process. Overall quality of the automation status was identified as (35\%) There was one library which was using commercial software and all other fully automated libraries were using KOHA open source software. Ten percentages $(10 \%)$ of the libraries were in poor status. However, a major revolution was identified in several poor status libraries that they would start to developing their automation with KOHA open source software in future.

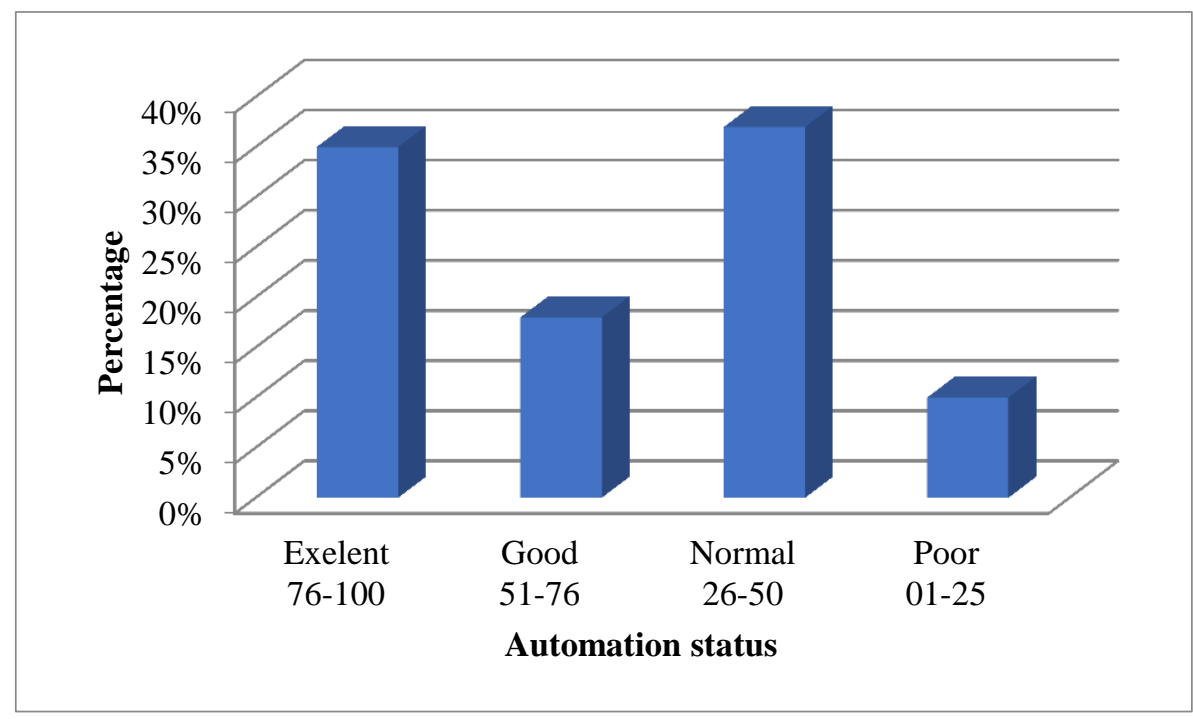

Figure 1: Status of University Library Automation in Sri Lanka

To be successful in the automation process libraries should utilize all modules of the library software. But as Figure 2 shows not all the University Libraries have utilized every available module in the automation software to automate their functions. Majority of Libraries have utilized cataloguing (100\%), circulation (78\%) and Open Access Catalogue (77\%). Among them $48 \%$ of libraries utilized acquisition modules and very few libraries (33\%) utilized budgeting module. Limited utilization of modules affects overall performance of the university library automation. 


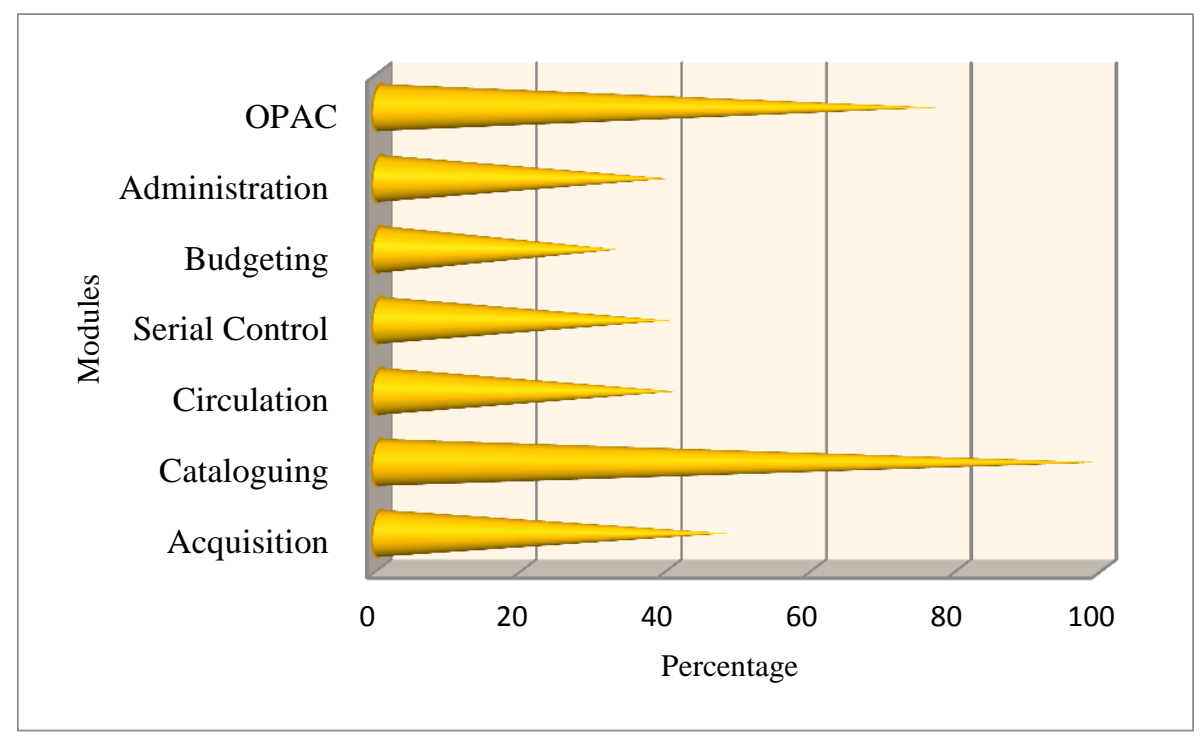

Figure 2: Use of Library Automation Modules

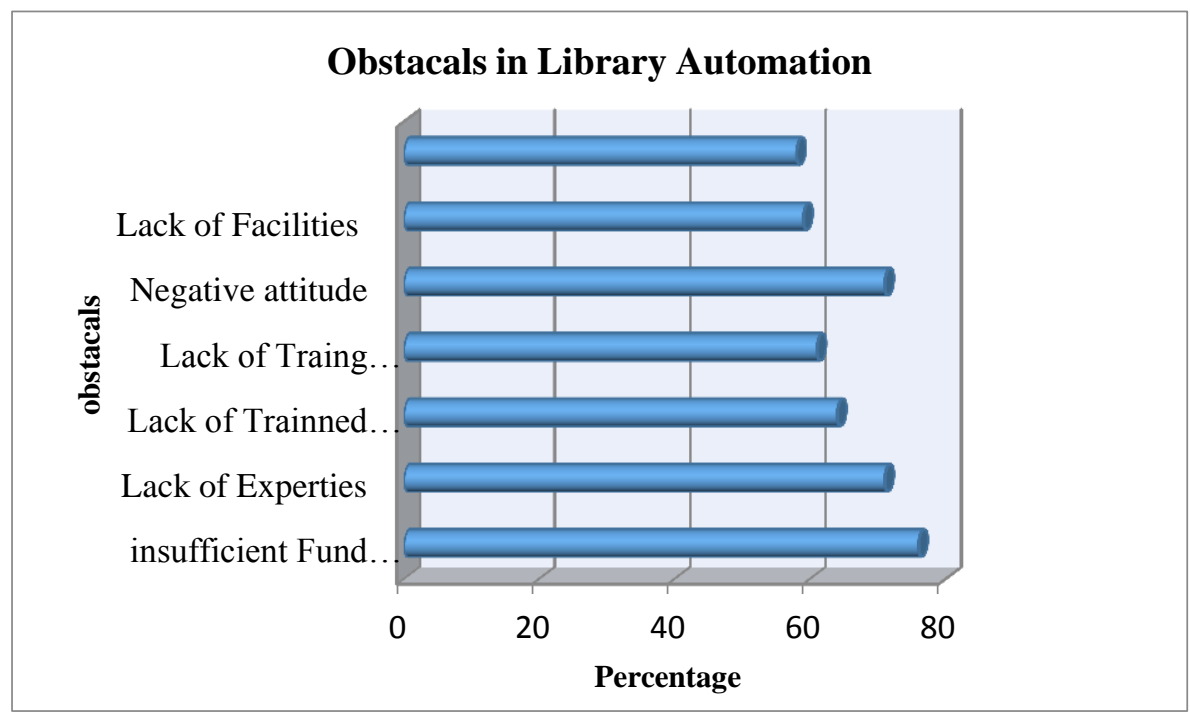

\section{Figure 3: Obstacles in Library Automation}

Second objective of this study is to identify the problems associated with existing system. For this purpose, some critical issues in automation were identified in the study and priority levels related to each university library were considered. There were several challenges and obstacles. Insufficient 
fund allocation was the major barrier of the automation (76\%). Lack of expertise and commitments also identified as common barriers in academic libraries $(71 \%)$.The respondents expressed that they lack experienced human resources such as experts in the areas of database management system troubleshooting and computer network management (64\%).Further, warranty and distance from the vendor were also identified as barriers. Negative attitude of the mother institute also $(71 \%)$ identified as an obstacle.

Almost all libraries have faced pre-automation and post automation problems. Lack of trained staff, hesitancy in learning computer applications and technical problems were issues faced in the initial stage of automation. Following suggestions are important to overcome the above obstacles.

1) University Libraries required more funds. To purchase Information Technology equipment, in this regard the UGC Sri Lanka should provide sufficient funds for Library development.

2) Information technology based library and information science education should be provided in BA and MSc level.

3) Conducting in-house training programmes on a part time basis would help the staff members to practice automation skills.

4) Exploitation of Open-Source Software in Library automation helps overcoming basic challenges. This process should be authorized by the UGC, imposing standardized and uniform directives on usage and application policies of OSS in Sri Lankan Libraries.

5) Library staff no more immune to concerns over automation than any other service; They are concerned about job losses. While survey found that the introduction of automation had created more work for some staff because the effectiveness of the system made it possible to carry out tasks that were not previously considered feasible. Librarians must therefore be capable enough to introducing and managing the change successfully through participative decision making, communication skills and understanding.

\section{Conclusion}

In conclusion, this survey revealed all the Sri Lankan university libraries initially started to use cataloguing module instead of automating entire library services. At the beginning, library automation process was not much 
favored by the librarians but after year 2000 automation became a buzz word. Introduction of the OSS and recruiting ICT staff to university libraries improved efficiency and effectiveness of automation. It also improved the quality of production and operating libraries during nonstandard hours. With these benefits, higher authorities of the university system tried to support the libraries without any hesitation. According to results of the study most of the universities were provided with funds through university allocation for their automation process.

Present status of the Sri Lankan university library automation is that almost all the university libraries have started automating their functions and services. KOHA is the popular library software among the Sri Lankan university libraries. However, percentage of fully automated libraries is less than 60\%. Almost all libraries have faced pre-automation and post automation problems. Insufficient funds, hesitancy in learning computer application and technical problems were issues faced in the initial stage of automation. Finally for the successful implementation of an integrated automated library system all key factors should be in place, support from Sri Lanka UGC for administrative, functions and other physical infrastructure requirements (Hardware / Software /Network Connections /Consultancy/ Electricity supply), considering user behavior staff skills is vital important along with understanding managerial skills through coordination of the project. 


\section{References}

Kent, A, (1997), Encyclopedia of Library \& Information Science, New York, Marcel Dekkar,1997.

Patel K \& Patel B.A, (2012) Library Automation Planning, Indian Journal of Research, 1 (12), 92-94

Raman Nair, R. (1995): Preface to academic library automation, New Delhi, Ess Ess Publication.

Ravikumar M. N \& Ramanan, T. (2014) Status and Prospects of Library Automation in Sri Lankan Universities: A Perspective, European Academic Research, 1(12), 5770-5785

Talagala, D. \& Gamage, P. (2003) Library automation in Sri Lanka: An overview, Retrieved from http://ir.inflibnet.ac.in:8080/jspui/hanle/1944/190

Uddin, H., (2009) Library automation: A study of the AIC, INSDOC and National libraries of Bangladesh. p.42

Wijayaratne, A, (2005). Automation of Library Functions with special reference to circulation System adopted the Library of Open University of Sri Lanka, Journal of the University Librarians Association of Sri Lanka, 9, $12-22$ 